\title{
Diffusion of PAH in potato and carrot slices and application for a potato model
}

Trapp, Stefan; Cammarano, A.; Capri, E.; Reichenberg, F.; Mayer, Philipp

Published in:

Environmental Science \& Technology (Washington)

Link to article, DOI:

$10.1021 / \mathrm{es} 0624180$

Publication date:

2007

Link back to DTU Orbit

Citation (APA):

Trapp, S., Cammarano, A., Capri, E., Reichenberg, F., \& Mayer, P. (2007). Diffusion of PAH in potato and carrot slices and application for a potato model. Environmental Science \& Technology (Washington), 41(9), 3103-3108. https://doi.org/10.1021/es0624180

\section{General rights}

Copyright and moral rights for the publications made accessible in the public portal are retained by the authors and/or other copyright owners and it is a condition of accessing publications that users recognise and abide by the legal requirements associated with these rights.

- Users may download and print one copy of any publication from the public portal for the purpose of private study or research.

- You may not further distribute the material or use it for any profit-making activity or commercial gain

- You may freely distribute the URL identifying the publication in the public portal

If you believe that this document breaches copyright please contact us providing details, and we will remove access to the work immediately and investigate your claim. 
Supporting Information

\section{Diffusion of PAH in potato and carrot slices and application for a potato model}

Stefan Trapp, Anita Cammarano, Ettore Capri, Fredrik Reichenberg and Philipp Mayer

1) Figure of experimental system

2) Calculation of velocity rate constant $\mathrm{k}$

3) Diffusion in gas phase

4) Alternative way to derive the equation for the velocity rate constant ratio

5) Earlier version of a potato model 


\section{1) Figure of experimental system}

Microchambers (Figure SI 1) for the measurement of mass transfer by partitioningdiffusion-partitioning were assembled by placing the thin plant slices between a contaminated PDMS disk (the source) and a clean PDMS disk (the sink). For the water measurements, the two disks were separated by inserting a steel washer with a thickness of $100 \mu \mathrm{m}$, which served as a circular spacer and as a gasket for keeping the water in place. The whole microchamber was conveniently assembled on a horizontal glass plate with steel backing and pressed together using a magnet.
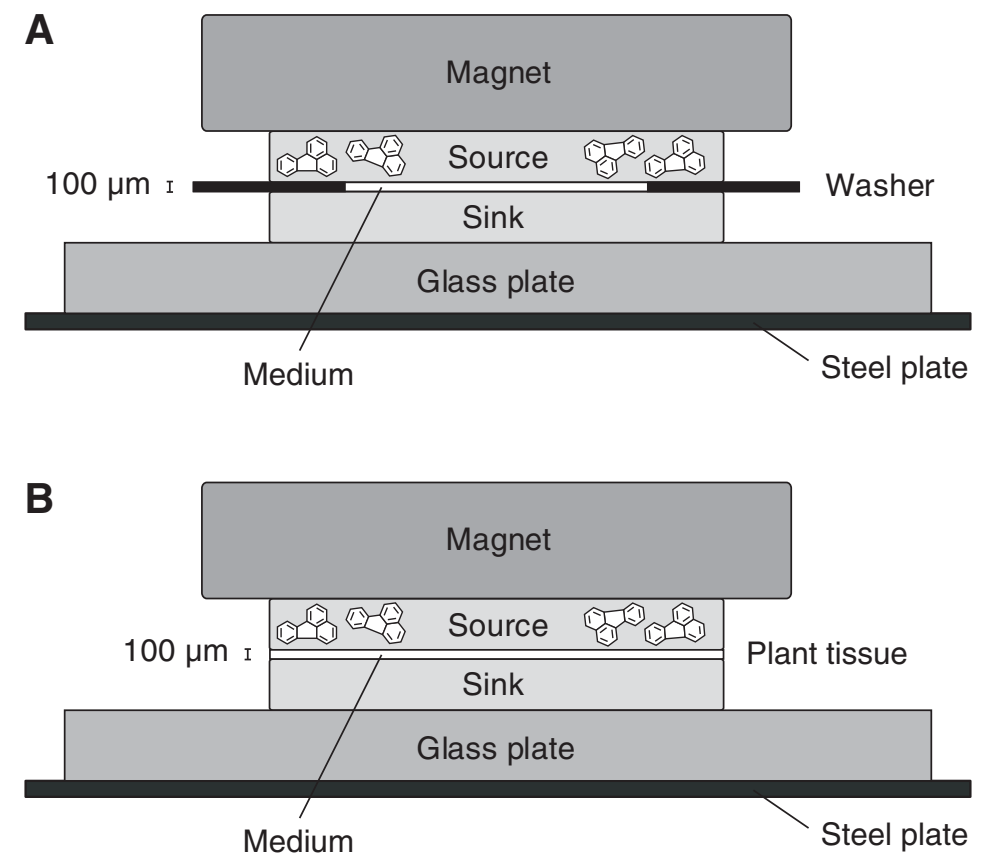

FIGURE SI 1. (A) Cross section of the experimental apparatus when operated with water and other liquids. (B) Cross section of the experimental apparatus when applied to plant tissue. 


\section{2) Calculation of velocity rate constant $k$}

The mass balance of the system was described in Mayer et al. (2005). With $m_{1}$ and $m_{2}$ are the mass in disk 1 and 2 at time $\mathrm{t}, m_{0}$ is the initial mass (in disk 1 ), and $a$ is a constant $\left(\mathrm{s}^{-1}\right)$ describing the exchange velocity follows

$m_{1}(t)=1 / 2 m_{0}+1 / 2 m_{0} \times e^{-2 a t}$
$m_{2}(t)=1 / 2 m_{0}-1 / 2 m_{0} \times e^{-2 a t}$

or, with concentration $C$ as mass $m$ divided by volume $V$

$C_{1}(t)=1 / 2 C_{0}+1 / 2 C_{0} \times e^{-2 a t}=1 / 2 C_{0} \times\left(1+e^{-2 a t}\right)$

$C_{2}(t)=1 / 2 C_{0}-1 / 2 C_{0} \times e^{-2 a t}=1 / 2 C_{0} \times\left(1-e^{-2 a t}\right)$

In analogy to Fick's 1st Law of diffusion, we may also express the differential equation as

$\frac{d C_{2}}{d t}=\frac{A}{V} \frac{K \times D}{\Delta x} C_{1}-\frac{A}{V} \frac{K \times D}{\Delta x} C_{2}$

where $A$ is the surface area $\left(\mathrm{m}^{2}\right), V$ is the volume of the disc $\left(\mathrm{m}^{3}\right), \Delta \mathrm{x}$ is the thickness of the layer $(\mathrm{m}), K$ is the partition coefficient between the solution in the boundary layer and the polymer $\mathrm{K}_{\text {Medium,PDMS }}=1 / \mathrm{K}_{\mathrm{PDMS}, \text { Medium }}$ and $D$ is the effective diffusion coefficient $\left(\mathrm{m}^{2} \mathrm{~s}^{-1}\right)$ 
of the substance in the boundary layer. The velocity constant $a\left(\mathrm{~s}^{-1}\right)$ from before can be identified as

$a=\frac{A}{V} \frac{K \times D}{\Delta x}$

The relation between the experimentally fitted rate $k$ and the velocity constant $a$ is

$$
k=2 \times a=2 \times \frac{A}{V} \times \frac{D}{K_{P D M S, \text { Medium }} \times \Delta x}
$$

The following input data are used. The layer thickness $\Delta x$ was set to $100 \mu \mathrm{m}(0.0001 \mathrm{~m})$, the disk volume $V$ was set to $1.7 \times 10^{-8} \mathrm{~m}^{3}$, the exchange area $A$ was set to $1.26 \times 10^{-5} \mathrm{~m}^{2}$ for water and $2.83 \times 10^{-5} \mathrm{~m}^{2}$ for plant slices. The partition coefficient $K_{P D M S \text {,Water }}$ was calculated from Mayer et al. (2000):

$\log K_{\text {PDMS_Water }}=\log K_{\text {OW }}-0.91$

For fluoranthene and phenanthrene, measured $K_{P D M S, \text { Water }}$-values were available (12302 and 3020 , respectively) from that reference.

The diffusion coefficients of chemicals can be related to the square root of the molar mass $M\left(\mathrm{~g} \mathrm{~mol}^{-1}\right)$. The diffusion coefficient of the chemical in pure water $D_{W}$ related to the diffusion coefficient of oxygen in water $D_{O_{2}}$ is (Trapp \& Matthies 1998) 
$D_{W}=D_{O 2} \times \frac{\sqrt{32}}{\sqrt{M}}$

where $D_{O 2}$ is the diffusion coefficient of oxygen $\mathrm{O}_{2}\left(\mathrm{M}=32 \mathrm{~g} \mathrm{~mol}^{-1}\right)$ in water and is 1.728 $\mathrm{x} 10^{-4} \mathrm{~m}^{2} \mathrm{~d}^{-1}$. Diffusion coefficients in plant slices were calculated as described:

$D_{P}=D_{W} \times T_{W} \times f_{W}$

Table SI1 shows the physico-chemical data used and the measured and calculated k-values for water, Table SI2 for potato and carrot. The average ratio between measured and calculated $\mathrm{k}$ for all media is 1.14 , meaning the deviation of the calculated value from the measured value is in average $14 \%$. The maximum deviation (PHT, water) is $38 \%$. In recent work (Mayer et al. 2005), $k$ for FLT and water was measured to $0.00423 \mathrm{~h}^{-1}$. This means, measurements have improved; probably due to increasing routine with the apparatus. 
TABLE SI1: Physico-chemical properties of compounds, measured and calculated rates $k$ $\left(h^{-1}\right)$ for water and the ratio of both.

\begin{tabular}{lrrrrr}
\hline Compound & $\mathbf{M}^{*}$ & log $\mathbf{K}_{\text {ow }}{ }^{* *}$ & measured $\mathbf{k}$ & calculated $\mathbf{k}$ & ratio \\
\hline NAP & 128.19 & 3.37 & 0.199 & 0.203 & 0.98 \\
PHEN & 178.24 & 4.46 & 0.0136 & 0.0099 & 1.38 \\
ANT & 178.24 & 4.45 & 0.0101 & 0.0077 & 1.32 \\
FLT & 202.26 & 5.13 & 0.00346 & 0.00345 & 1.00 \\
Average & & & & & 1.17 \\
\hline
\end{tabular}

* Rippen (2001); ** DeMaagd et al. (1998)

TABLE SI2: Measured and calculated rates $\boldsymbol{k}$ for potato and carrot and the ratio.

\begin{tabular}{lrrrrrr}
\hline Compound & $\begin{array}{r}\text { measured } \\
\text { k potato }\end{array}$ & $\begin{array}{r}\text { calculated } \\
\text { k potato }\end{array}$ & ratio & $\begin{array}{r}\text { measured } \\
\text { k carrot }\end{array}$ & calculated & k carrot \\
\hline NAP & 0.191 & 0.261 & 0.73 & 0.405 & 0.404 & ratio \\
PHEN & 0.0158 & 0.0128 & 1.24 & 0.0242 & 0.0197 & 1.00 \\
ANT & 0.0125 & 0.0099 & 1.26 & 0.0198 & 0.0153 & 1.29 \\
FLT & 0.00499 & 0.00445 & 1.12 & 0.00746 & 0.00688 & 1.08 \\
Average & & & 1.09 & & & 1.15 \\
\hline
\end{tabular}




\section{3) Diffusion in gas phase}

The method is based on Trapp (2006), but has already been used in Trapp \& Matthies (1998) for soil. It is derived from Jury's method (Jury et al. 1983). Only the dissolved fraction of chemical, $f_{W}$, and the gaseous fraction of chemical, $f_{G}$, are mobile and can diffuse, while the adsorbed fraction of the chemical is considered immobile. This is due to the comparatively low diffusion coefficients in solids, which have values of about $10^{-14} \mathrm{~m}^{2}$ $\mathrm{s}^{-1}$ (Trapp \& Matthies 1998). We had described diffusion through potato tissue by Fick's $1^{\text {st }}$ Law of diffusion (eq. 5):

$\frac{d m}{d t}=-A_{P} \times \frac{D_{P}}{\Delta x} \times\left(C_{P, 1}-C_{P, 2}\right)$

where $A_{P}$ was the surface area of the plant slice $\left(\mathrm{m}^{2}\right), D_{P}$ was the effective diffusion coefficient of the chemical in plant tissue $\left(\mathrm{m}^{2} \mathrm{~h}^{-1}\right)$ and $C_{P 1}$ and $C_{P 2}$ were the concentrations in the plant slice at the upper (1) and lower (2) interface to the PDMS-disk.

We may write instead

$\frac{d m}{d t}=-\frac{A_{P}}{\Delta x} \times\left[D_{W} \times T_{W} \times\left(C_{W, P, 1}-C_{W, P, 2}\right)+D_{G} \times T_{G} \times\left(C_{G, P, 1}-C_{G, P, 2}\right)\right]$

where $D_{W}$ is the diffusion coefficient of the chemical in pure water and $D_{G}$ is the diffusion coefficient in pure gas phase. The diffusion coefficients of chemicals can be related to the 
square root of the molar mass $M\left(\mathrm{~g} \mathrm{~mol}^{-1}\right)$. For $D_{W}$, we use the same relation as in section 2 SI. For the estimation of $D_{G}$, the diffusion coefficient of water vapour $D_{H 2 O}$ in air is used, with $D_{H 2 O}=2.22 \mathrm{~m}^{2} \mathrm{~d}^{-1}($ Trapp \& Matthies 1998)

$D_{G}=D_{H 2 O} \times \frac{\sqrt{18}}{\sqrt{M}}$

In porous solids (such as plant tissue), the diffusion is hampered by a "labyrinth factor", named tortuosity $T$. This tortuosity is estimated by the method of Millington and Quirk (cited in Jury et al. 1983). $T_{W}$ is the tortuosity in the water pores of the plant tissue, and $T_{G}$ is the tortuosity of the gas-filled pores. As mentioned, the expressions are not unit-true, which is ignored here.

$$
\begin{aligned}
& T_{W}=\frac{W_{P}^{10 / 3}}{\left(W_{P}+G_{P}\right)^{2}} \\
& T_{G}=\frac{G_{P}^{10 / 3}}{\left(W_{P}+G_{P}\right)^{2}}
\end{aligned}
$$

$C_{W, P}$ and $C_{G, P}$ are the concentration in the water and the gas phase of the plant tissue at the interface with the source (1) and sink (2) disks. Gradients and diffusion coefficients in the above equation are related to the water and gas phase. 
The fraction of chemical $f_{W}\left(\mathrm{mg} \mathrm{L}^{-1}: \mathrm{mg} \mathrm{kg}^{-1}\right)$ dissolved in the water $W_{P}\left(\mathrm{~L} \mathrm{~kg}^{-1}\right)$ of the plant (the ratio between concentration in water phase of the plant tissue to total concentration) is

$$
f_{W}=\frac{C_{W, P}}{C_{P}}=\frac{W_{P}}{K_{P W}}
$$

The fraction of chemical $f_{G}\left(\mathrm{mg} \mathrm{L}^{-1}: \mathrm{mg} \mathrm{kg}^{-1}\right)$ present in gas pores $G_{P}\left(\mathrm{~L} \mathrm{~kg}^{-1}\right)$ of the plant (the ratio between concentration in gas phase of the plant tissue to total concentration) is

$$
f_{G}=\frac{G_{P} \times K_{A W}}{K_{P W}}
$$

The flux across the layer can then be related to the total concentration in the plant tissue:

$$
\frac{d m}{d t}=-\frac{A_{P}}{\Delta x} \times\left(D_{W} \times T_{W} \times f_{W}+D_{G} \times T_{G} \times f_{G}\right) \times\left(C_{P, 1}-C_{P, 2}\right)
$$

We can now define effective diffusion coefficients $D_{\text {eff }}$ related to the total concentration. For diffusion in the water pores of the plant $D_{W, \text { eff }}$

$D_{W, e f f}=D_{W} \times f_{W} \times T_{W}$

and for diffusion in the gas pores $D_{G, \text { eff }}$ 
$D_{G, e f f}=D_{G} \times f_{G} \times T_{G}$

The sum of $D_{W, \text { eff }}$ and $D_{G, \text { eff }}$ gives the diffusion coefficient of the chemical in plant tissue $D_{P}\left(\mathrm{~m}^{2} \mathrm{~d}^{-1}\right)$, which we had used in eq. 5 and at the beginning of this section

$D_{P}=D_{W, e f f}+D_{G, e f f}$

Furthermore, $D_{W, e f f}$ and $D_{G, \text { eff }}$ relate to the same gradient and can therefore be directly compared.

\section{Example potato, fluoranthene}

$\log K_{O W}=5.23$ (DeMaagd et al. 1998) and $M=202.26 \mathrm{~g} \mathrm{~mol}^{-1}$ (Rippen (2001)

$\mathrm{W}=0.778 \mathrm{~L} \mathrm{~kg}^{-1}$

$\mathrm{G}=0.04 \mathrm{~L} \mathrm{~kg}^{-1}$

$D_{\mathrm{W}}=6.87 \times 10^{-5} \mathrm{~m}^{2} \mathrm{~d}^{-1}$

$D_{G}=0.66 \mathrm{~m}^{2} \mathrm{~d}^{-1}$

$\mathrm{K}_{\mathrm{AW}}=0.00043$

$\mathrm{K}_{\mathrm{PW}}=14.2$ (Eq. 20, main article)

$f_{W}=0.055$

$\mathrm{f}_{\mathrm{G}}=1.81 \times 10^{-6}$ 
$\mathrm{T}_{\mathrm{W}}=0.66$

$\mathrm{T}_{\mathrm{G}}=3.2 \times 10^{-5}$

$D_{W, e f f}=D_{W} \times f_{W} \times T_{W}=2.39 \times 10^{-6} \mathrm{~m}^{2} \mathrm{~d}^{-1}$

$D_{G, e f f}=D_{G} \times f_{G} \times T_{G}=2.55 \times 10^{-11} \mathrm{~m}^{2} \mathrm{~d}^{-1}$

As can be seen, diffusion in gas phase does practically not contribute to the overall diffusion.

In neglecting gas phase completely $(\mathrm{G}=0), f_{W}$ and $D_{W}$ remain unchanged, but a small difference is introduced by $T_{W}$ being 0.73 (higher!). This difference is about $10 \%, D_{W, \text { eff }}=$ $2.51 \times 10^{-6} \mathrm{~m}^{2} \mathrm{~d}^{-1}$

Wild et al. $(2005,2006)$ visualized the movement of phenanthrene in roots and leaves using two-photon excitation microscopy. The movement in maize and wheat roots appeared to be via the apoplastic pathway. The movement in the epidermis of maize leaves was probably apoplastic, too, while in the epidermis of spinach leaves, symplastic (inside the cell) movement seemed to dominate. From our experiments, we cannot distinguish between apoplastic or symplastic movement; however, since there is aqueous solution inside the cells, but also around the cells, both transport pathways are possible. 


\section{Literature Cited in Sections 2 and 3}

Mayer et al. (2005) is reference (5)

Mayer et al. (2000) is reference (7)

Trapp \& Matthies (1998) is reference (14)

Trapp (2006) is reference (8)

Jury et al. (1983) is reference (9)

Rippen (2001) is reference (24)

DeMaagd et al. (1998) is reference (13)

Wild, E.; Dent, J.; Thomas, G.O.; Jones, K.C. Direct observation of organic contaminant uptake, storage, and metabolism within plant roots. Environ. Sci. Technol. 2005, 39, 36953702.

Wild, E.; Dent, J.; Thomas, G.O.; Jones, K.C. Visualizing the air-to-leaf transfer and within-leaf movement and distribution of phenanthrene: further studies utilizing twophoton excitation microscopy. Environ. Sci. Technol. 2006, 40, 907-916. 


\section{Alternative way to derive the equation for the velocity rate constant ratio}

We showed that the ratio of transfer through plant tissue to the transfer through water is described by equation 13 :

$\frac{k_{\text {Plant }}}{k_{\text {Water }}}=\frac{A_{P}}{A_{W}} \times W^{7 / 3}$

where A denotes area, $\mathrm{W}$ water content of plant tissue and $\mathrm{P}$ and $\mathrm{W}$ are indices for plant tissue and water.

There is a second, independent way to arrive at this surprising result. Assume that the mass of chemical in the disks is always much higher than the mass of chemical in the slice between the disks (a condition which is fulfilled, (ref 5)). Then, the freely dissolved concentration $\left(C_{\text {free }}\right.$ in ref (18)) of the chemical in the water phase at the interface between disk and slice is the same, independent of whether the slice consists of pure water or plant tissue with water filled pores.

$$
\frac{d m}{d t}=-A_{W} \times \frac{D_{W}}{\Delta x} \times\left(C_{W 1}-C_{W 2}\right)
$$

where $C_{W}$ denotes the concentration in the water phase at the upper and lower interface. With a slice of plant tissue, the corresponding flux equation through the water phase of the plant tissue is 
$\frac{d m}{d t}=-A_{W P} \times \frac{D_{W} \times T}{\Delta x} \times\left(C_{W 1}-C_{W 2}\right)$

where $T$ is again $W^{4 / 3}$ and $A_{W P}$ is the surface area of the water phase of the plant. With $A_{W P}$ $=A_{P} x W$ follows

$\frac{d m}{d t}=-A_{P} \times W \times \frac{D_{W} \times W^{4 / 3}}{\Delta x} \times\left(C_{W 1}-C_{W 2}\right)$

Comparing the alternative flux equations for water and plant tissue gives the same result as before:

$\frac{k_{\text {Plant }}}{k_{\text {Water }}}=\frac{A_{P}}{A_{W}} \times W^{7 / 3}$

One consequence of the equation is that diffusion through potato tissue from source disk to sink disk should be faster than diffusion through carrot, because potato has more pore water space - even though the sorption of the compound to the carrot tissue may be stronger than the sorption to the potato tissue. Maybe it is easier to follow this mathematical way to that counter-intuitive result, which was confirmed by the measurements. 


\section{5) Earlier version of a potato model}

The authors and others have earlier used another type of potato model (Samsøe-Petersen et al. $2003=$ ref (2), Kulhanek et al. 2005). It also assumes diffusion via peel as only source of contamination of the potato and treats the problem as diffusion into a sphere, but in dependency of space and time.

Mathematical concept of the earlier potato model. Diffusion into a sphere can be considered as symmetrical from all sides. Molecules from all directions arrive at the same time at the midpoint. Mathematically, this is identical to a reflection at the center of the sphere (Figure SI 2).

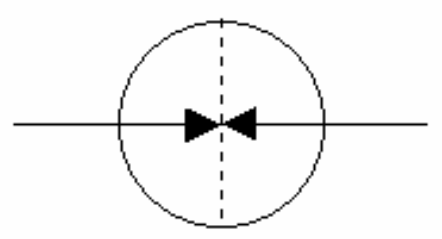

Figure SI 2: Image of the diffusion process into the sphere.

Thus, for one dimension, the boundary conditions are identical to the diffusion in a plane with reflection at a fixed boundary. This problem was solved by Carslaw and Jaeger (1933, p. 309). For the region $0<x<r$, the initial concentration is zero. There is no flux at $x=0$, and $x=r$ is maintained at constant concentration $C_{0}$ for $t>0$. The solution is

$C(x, t)=C_{0} \sum_{n=0}^{\infty}(-1)^{n} \operatorname{erfc} \frac{(2 n+1) r-x}{\sqrt{4 D t}}+C_{0} \sum_{n=0}^{\infty}(-1)^{n} \operatorname{erfc} \frac{(2 n+1) r+x}{\sqrt{4 D t}}$ 
Interprete $x=0$ as the midpoint, and $r$ as the radius. The sphere is divided into $n$ layers of thickness $d x$. The average concentration in the sphere is found by summing up the concentrations at each $0<1 / 2 d x+i d x \leq r$, where $i=0, \ldots, n-1$, weighted with the volume fraction of each layer of the whole sphere volume. The result depends therefore to some degree on the $\mathrm{x}$-grid.

Parameterization of the earlier model. The earlier model needs four parameters, namely radius $r$, time period $t$, concentration at $x=r$ (peel) $C_{0}$, and diffusion coefficient $D$ in the potato. The radius can be set to $4 \mathrm{~cm}$, as before. The time period $t$ is set to 60 days (time between formation of tubers and harvest). The concentration $C_{0}$ is identical to the equilibrium concentration potato-soil (named $B C F$ in the manuscript). The diffusion coefficient in potato was in principle calculated by the same equations and with the same data as in the new concept. Only the tortuosity had been set to 0.01 , based on empirical data for wood and the volatile chemical toluene (Mackay \& Gschwend 2000). We know now form the results of the experiments, that this value was too low for PAH diffusion in potato pore water (potato has a higher water content, but a lower gas pore content than wood). We will therefore show the outcome of simulations with the old $T=0.01$ and with the new $T=W^{4 / 3}$.

Figure SI 3 shows the calculated concentration ratio between potato and soil for phase equilibrium $(\mathrm{BCF})$, the new approach with growth $\left(\mathrm{BCF}^{*}\right)$, the old approach with correct tortuosity (BCF old), and for the old approach with the false tortuosity $(\mathrm{BCF}$ old $\mathrm{T}=0.01)$. 
The simulation is similar to Figure 3 in the article, but made with an organic carbon content of $2 \%$. As can be seen, the difference is not too big for $\log K_{O W}<5$. For more lipophilic compounds, all model results are lower than equilibrium, and the results differ more. The outcome of the earlier model depends very much on the diffusion coefficient (and therefore on the tortuosity that is used to calculate it): with the low tortuosity, a much lower uptake is predicted than with the high tortuosity. From the comparison to field data is known that measured concentrations in potato for compounds with $\log K_{O W} \geq 6$ were near or below the outcome of the new model. Thus, the earlier model concept gave quite accurate predictions, however, with false input data.

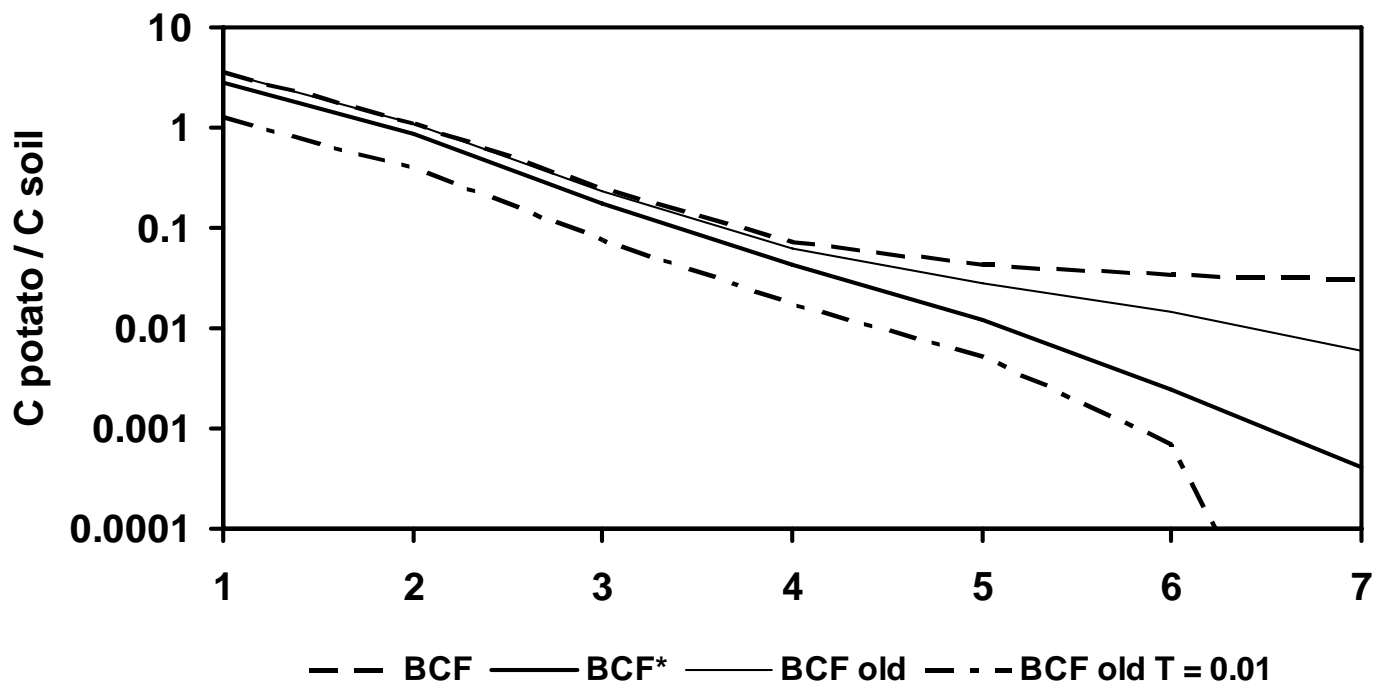

Figure SI 3: Calculated concentration ratio between potato and soil for phase equilibrium (BCF), new approach with growth (BCF*), old approach with correct tortuosity (BCF old) and old approach with false tortuosity (BCF old $\mathrm{T}=0.01$ ); simulations with $2 \% \mathrm{f}_{\mathrm{OC}}$.

Conclusion. The earlier solution for the uptake of chemicals in potato is fundamentally different from the new one. Similar as with the new concept, a reduction of 
bioconcentration in potato for compounds with high $\log K_{O W}$ was found, and this reduction was due to diffusion limitation. But while in the new version, this is due to growth-dilution in the steady-state, it was due to non-completed diffusion in the earlier version.

In comparison to the earlier potato model, the new concept is of convenient simplicity. Besides, it allows the addition of relevant processes, such as $1^{\text {st }}$-order metabolism. The results are - if correct input data are used - closer to the measured data and therefore more realistic. Except in cases where the concentration distribution within the potato needs to be known as a function of the distance from the peel, the new concept is therefore preferable.

\section{Literature Cited in this Section}

Carslaw, H.S.; Jaeger, J.C. Conduction of heat in solids. At the Clarendon press: Oxford, $2^{\text {nd }}$ ed.

Kulhánek, A.; Trapp, S.; Sismilich, M.; Janků, J.; Zimová, M. Crop-specific human exposure assessment for polycyclic aromatic hydrocarbons in Czech soils. Science of the Total Environment 2005, 339, 71-80.

Mackay, A.A.; Gschwend, P.M. Sorption of monoaromatic hydrocarbons to wood. Environ. Sci. Technol. 2000, 34, 839-845.

Samsøe-Petersen, L.; Rasmussen, D.; Trapp, S. Modellering af optagelse af organiske stoffer i grøntsager og frugt. Rapport til Miljøstyrelsen, Miljøprojekt Nr 765 2003, 2003, Appendix C (appendix in English). Ref (2) in the article. 